\title{
La construcción narrativa de la realidad cotidiana. Una revisión desde los media frames
}

\section{The narrative construction of everyday reality. A review from the media frames}

\author{
Salomé Sola-Morales. Universidad Santiago de Chile
}

Recibido: 23-XII-2013 - Aceptado: 12-III-2014

Resumen:

El objetivo principal de este ensayo científico es presentar una revisión argumentada acerca de los media frames y cuestionar el vínculo entre los medios de comunicación y la realidad cotidiana. En primer lugar, ofrecemos algunas claves teórico-comprensivas que nos permiten esbozar los fundamentos ontológicos de la realidad cotidiana. En segundo lugar, ponemos de manifiesto el carácter subjetivo, comunicativo y narrativo de la misma, obviado por algunas propuestas teóricas. En tercer lugar, analizamos la incidencia de los medios de comunicación en la construcción de la realidad. En cuarto lugar, subrayamos el alcance de los media frames, tanto en la fase de configuración mediática (producción) como en la de refiguración (recepción). Finalmente, a modo de conclusión, remarcamos la necesidad de cuestionar interesantes interrogantes que este campo de estudio aún plantea.

Palabras clave:

Realidad cotidiana; media frames; comunicación; narración.

Abstract:

The main aim of this scientific essay is to present an overview about "media frames", and to question the link between media discourse and quotidian reality. Firstly, we explain some key scientific concepts and we refer to relevant literature about ontological basics of quotidian reality. Secondly, we put into consideration, the subjective, communicative and narrative condition of reality, sometimes undervalued by some theories. Thirdly, we analyse the incidence of the media discourse in the construction of reality. Fourthly, we underlined the scope of "media frames", both in the configuration (creation) and in the refiguration (reception) of media narratives. The general conclusion we have reached is that this field of study still raises interesting challenges and questions that should be investigated.

Key-words:

Quotidian reality, media frames, communication, narration. 


\section{Introducción}

El vínculo entre los medios de comunicación y la realidad ha sido abordado en las últimas décadas desde interesantes enfoques y perspectivas (Carter, 2013; Chillón, 2007; Duch y Chillón, 2012; Dunn, 1977; Ericson, 1998; Gamson et al., 1992; Frunza, 2011; Hartkey, 1996; Luhmann, 2000; Pintos, 2005; Van del Bulck, 1999 o Watzlawick, 2003). No obstante, consideramos que aún falta cierto consenso teórico en este campo de estudio que impide un desarrollo más amplio del mismo. Esto quizás se deba a que en ocasiones no se terminan de clarificar ciertas cuestiones epistemológicas básicas como qué es la realidad o a qué tipo de realidad no estamos refiriendo: ¿la realidad del orbe físico? ¿la subjetiva? ¿la colectiva? ¿la personal? En este sentido, la falta de una definición compartida hace que cada investigador termine optando por un lineamiento individual. Ciertamente es complejo -por no decir imposible- definir este término que ha sido objeto de reflexión de numerosos teóricos desde ámbitos de las ciencias sociales como la Filosofía, la Psicología o la Sociología, por mencionar las disciplinas más afines a los Estudios de Comunicación.

Por ello, se hace necesario seguir reflexionando acerca de los fundamentos ontológicos de la realidad para poder comprender el alcance de los medios de comunicación en la construcción de la misma. Con el propósito de evitar posibles ambigüedades iniciales es preciso clarificar que nosotros concretamente aquí nos referiremos a la llamada realidad cotidiana, es decir, la del quehacer humano propiamente, como la ha llamado Jerome Bruner (1996). Ésta más que ser una entidad que pertenece al mundo físico o natural, como podría pensarse, es una construcción simbólica, social y psicológica de carácter comunicativo, esencial para comprender procesos de diversa índole tales como la configuración mediática de las identidades, los imaginarios, la memoria o la tradición (Sola Morales, 2012; 2013a, 2013b).

Decimos que la realidad cotidiana es una construcción simbólica ya que el ser humano comprende y construye su mundo mediante símbolos como diría Ernst Cassirer (1998). Es más, gracias a los símbolos puede el hombre dar existencia a la realidad compartida. Valga anunciar también que esta realidad es una experiencia mediada (Barbero, 1987; Duch y Chillón, 2012) y está estructurada en parte de manera social, discursiva y narrativa. Y los medios, según nuestro parecer, más que reflejarla-como si de espejos se tratasen- la producen y configuran en cuanto tal (Eco, 1986; Giddens, 1995). Ahora bien, cómo lo hacen es una cuestión difícil de resolver. Por eso la pregunta que guiará nuestra exploración, en este ensayo será: ¿Cómo configuran los relatos mediáticos la construcción de la realidad cotidiana?

Pero antes de nada, y sin optar por ninguna clase de dogmatismo, trataremos de responder qué es la realidad cotidiana desde nuestra perspectiva. A fin de esclarecer esta cuestión revisaremos algunos de los antecedentes de estos presupuestos básicos, fundamentales para comprender el alcance de los medios de comunicación en dicho proceso. Los aportes de la fenomenología schütziana y, sobre todo, la propuesta de dos de sus discípulos, Peter L. Berger y Thomas Luckmann serán clave para entender el fenómeno en cuestión (Carter, 2013). No obstante, su enfoque presenta algunas limitaciones (Van den Bulck, 1999) y desde nuestra perspectiva puede ser ampliado y completado, tal como proponemos en este ensayo científico. 
Ya que presentamos un ensayo teórico-argumentativo, valga precisar que la metodología utilizada será de tipo cualititativo y el foco de nuestra reflexión será, por tanto, la literatura científica acerca de la incidencia de los medios sobre la realidad cotidiana (media frames), paradigma sobre el que consideramos aún existe poca literatura en español. Con esta reflexión, pretendemos poner de manifiesto la importancia de esta temática y motivar a nuevas investigaciones futuras. Por ello, nuestro objetivo general será ofrecer una panorámica argumentada acerca de los media frames y su incidencia en la construcción de la realidad cotidiana. En cuanto a los objetivos específicos serían: ofrecer claves crítico-reflexivas sobre los fundamentos ontológicos de la realidad cotidiana; explorar el carácter carácter subjetivo, comunicativo y narrativo de la misma; esclarecer el alcance de los medios de comunicación en la construcción de dicha realidad; y, finalmente, analizar el potencial que ofrecen los media frames en la investigación en comunicación.

\section{Las realidades múltiples: una diversidad de órdenes}

Una de las dificultades que ha planteado a menudo el estudio de la realidad es que puede ser estratificada. Algunos investigadores no han dudado en clasificarla por su carácter objetivo o subjetivo, exterior o interior, natural o construido, por citar algunas categorías posibles (Berne, 1966). Desde luego, si algo es bien claro es que realidad no hay solo una. En todo caso puede que existan realidades múltiples, como diría Alfred Schütz siguiendo las huellas de William James. Ya en sus Principios de psicología, el psicólogo consideró que existen varios órdenes o "subuniversos" de realidad con su propio estilo y existencia. Ahora bien, Schütz (2003, p. 215) prefiere denominar a estos diversos estratos de realidad "ámbitos finitos de sentido", ya que para él lo que constituye la realidad no es la existencia ontológica de los objetos, propiamente, sino el sentido de nuestras experiencias, es decir, de nuestras acciones, actos y vivencias.

De esta manera, la vivencia subjetiva, como iremos viendo, es crucial para entender la configuración de la realidad individual y colectiva. No olvidemos que el padre de la fenomenología, Edmund Husserl, ya consideró que la erlebnis o vivencia es imposible de captar de manera absoluta porque fluye sin cesar; del mismo modo que lo hace la realidad cotidiana. A este respecto, Schütz (2003: 210) hace alusión al "mundo del ejecutar cotidiano" o "mundo al alcance" para describir aquel estrato que el individuo experimenta como "núcleo de su realidad". Este mundo de la realidad primordial o paramount reality, como él lo denomina, es el mundo exterior, el de las cosas físicas o de la acción. Y es articulado en relación a dos potencialidades u horizontes de significación: el de la recuperación, que él llama "mundo del alcance recuperable", ya que nos permite volver al pasado y actuar de un modo dado en el presente; y el mundo de la proyección o "mundo al alcance asequible", que nos permite anticipar actos, imaginar o idealizar lo que está por ocurrir.

No olvidemos que sus discípulos, Peter L. Berger y Thomas Luckmann, también parten de esta premisa al referirse al "universo simbólico", noción que vincula a los hombres con sus antecesores y sus sucesores. Así la existencia individual es trascendida por la pertenencia a un universo significativo común. Pero insertarse o existir en este mundo del ejecutar co- 
tidiano implica, necesariamente, comunicarse en él con otros, de manera intersubjetiva. En palabras de Schütz (2003: 213): "Comparto este mundo y sus objetos con Otros; tengo fines y medios en común con Otros; actúo con ellos en múltiples actos y relaciones sociales, controlando a los Otros y siendo controlado por ellos. Y el mundo del ejecutar es la realidad dentro de la cual se hacen efectivas la comunicación y el juego de las motivaciones mutuas".

Este será, años más tarde, el eje de la propuesta de Peter L. Berger y Thomas Luckmann (2008), para quienes el mundo de la vida cotidiana es real en tanto se construye socialmente, es decir, en tanto es originado en los pensamientos y acciones de los miembros de la sociedad y está sustentado como real por estos. Los investigadores realizan una distinción entre dos órdenes: la realidad social objetiva (el mundo real) y la subjetiva (imagen que las personas tienen de éste). Según ellos, para poder vivir y actuar en el mundo, cada persona tiene que internalizar e interpretar la realidad objetiva que es construida socialmente, ya que sólo adquiere sentido en cuanto es compartida intersubjetivamente.

\subsection{La aprehensión de la realidad cotidiana}

Sin embargo, no podemos olvidar que esta realidad cotidiana se organiza desde el aquí y el ahora concretos por una subjetividad en acto y, además, se halla arraigada en un cuerpo, en un sentido fenomenológico. A la luz de estos planteamientos podríamos afirmar que la vivencia de la realidad es también para nosotros eminentemente subjetiva.

De hecho, como ha expresado Jan van den Bulck (1999: 4), la distinción entre realidad objetiva y subjetiva sólo puede realizarse a un nivel teórico, ya que los individuos no realizan este tipo de distinciones en su vida diaria. Quizás, por eso, una de las preguntas clave que habríamos de plantearnos es precisamente: ¿Cómo los sujetos aprehenden o perciben esta realidad objetiva? Tal y como sugieren los discípulos de Schütz, los esquemas tipificadores son clave para comprender la manera en que la realidad es producida y la significación es el único modo de objetivar la subjetividad humana.

No olvidemos que los sujetos están continuamente rodeados de objetos y artefactos que proclaman las intenciones subjetivas y que están dotados de "semiosis ilimitada", como diría Charles Peirce. Aquí, la solución que dan Berger y Luckmann a la brecha dicotómica es la dialéctica, ya que proponen un proceso dialógico continuo entre lo individual y lo social, lo objetivo y lo subjetivo. Éste es quizás, para nosotros, el elemento más interesante de archiconocida La construcción social de la realidad, la coimplicación entre la facticidad social y la significación subjetiva, tan relegada a un segundo plano por el cientificismo positivista.

Para los fenomenólogos mencionados, la biografía de un individuo no puede separarse del contexto en el que se ubica, ya que el universo subjetivo se construye gracias a una serie de significados que están articulados objetivamente, pero tampoco es posible aproximarse a la estructura sin tener presentes a los individuos históricos que la constituyen. Por ello, para nosotros la objetivación tiene sentido en tanto es propuesta como un proceso mediante el cual las creaciones y expresio- 
nes humanas adquieren una existencia dada en el mundo social. No olvidemos que tal y como ha sugerido Albert Chillón (2007: 40): "A diferencia de la objetividad óntica que cabe a atribuir a las cosas y sucesos del orbe físico, genuinamente independientes de las acciones y designios del ser humano, la objetividad propia del mundo social posee un estatuto ontológico distinto, históricamente construido y derivado de ellos".

Otro investigador que ha estratificado niveles de realidad de forma muy interesante es John Searle (1997), quien ha afirmado que la realidad socialmente construida presupone una no socialmente construida. A saber que existen dos realidades coimplicadas: la primera, que es independiente de los deseos, creencias y necesidades cognitivas del ser humano y que se encuentra formada por 'hechos brutos'; y la segunda, dependiente del acuerdo humano y formada por 'hechos institucionales'. Mientras que la realidad bruta pertenece al orbe físico y es ontológica y epistémicamente objetiva; la realidad institucional es ontológicamente subjetiva y epistémicamente objetiva (Searle, 1997: 197). Así planteado, podemos afirmar que las normas, los valores e, incluso, las emociones colectivas son producidas objetivamente por la sociedad y aprehendidas subjetivamente por los individuos y los grupos. Y que estos, a su vez las convierten en objetivaciones que irán sedimentándose en forma de universos simbólicos, imaginarios o tradiciones compartidas.

Los hechos sociales, como han sugerido Lluís Duch y Albert Chillón (2012: 381), son hechos por, para y entre personas. Esta afirmación, que puede parecer tan evidente así planteado, pocas veces se ha proclamado de forma directa en el ámbito comunicativo, por ejemplo, y es la base de falacias retóricas como que la objetividad absoluta es posible y debe ser capturada y transmitida fielmente por los periodistas.

No obstante, a la hora de aplicar el modelo propuesto por Berger y Luckmann en La construcción social de la realidad, al estudio de la comunicación mediática, hallamos algunas limitaciones teóricas. La primera de ellas -tal y como ha sugerido Van den Bulck (1999) - es que los autores subestiman la importancia de las mediaciones mediáticas en la construcción de la realidad social. La segunda es que, a pesar de realizar una distinción entre diversos órdenes de realidad, como hemos visto, no prestan suficiente atención al carácter interpretativo de la realidad subjetiva. De hecho, para ellos, toda identificación subjetiva de la realidad se encuentra siempre ubicada dentro de un horizonte que implica un mundo social específico, que es el contexto en el cual los sujetos se insertan. Sin embargo, pertenecer a un mismo marco no implica, estrictamente, que la percepción de la realidad sea la misma, como veremos a continuación. Es más, como diría Lippmann (1922) las personas viven en un mismo mundo, pero piensan y sienten de manera diferente, por lo que sus realidades pueden variar mucho.

\section{La construcción psicológica y narrativa de la realidad cotidiana}

De hecho, el proceso de apropiación subjetiva de la realidad compartida evidencia la necesaria presencia de un sujeto que la experimenta y observa y, por tanto, la construye de manera psicológica. La presencia de este observador, como diría 
Humberto Maturana (1996), pone de manifiesto que la realidad no es independiente de quien la mira, efectúa y siente, sino que su construcción se produce en una necesaria coimplicación con quienes la empalabran ${ }^{1}$.

Para nosotros, la realidad cotidiana se estructura en parte de forma narrativa, como expresaría Jerome Bruner (1996). Desde esta perspectiva, la realidad nunca puede ser conocida sin la participación del observador, que es el que, con sus acciones o pensamientos, crea experiencias significativas de la realidad. Esta concepción de la realidad es parecida a la propuesta por los constructivistas Nelson Goodman (1984) y Paul Watzlawick (1988). Mientras que para el primero no existe ningún mundo real preexistente a la actividad mental humana y al lenguaje simbólico; para el segundo, "toda realidad es en el sentido más directo, la construcción de quienes creen que descubren e investigan la realidad" (2003: 7).

Los investigadores argumentan así contra la presencia de una única realidad absoluta y recuerdan que el observador es quien construye e inventa las diversas versiones de la realidad, que son fruto de la comunicación y del intercambio simbólico. Tal y como ha expresado Brumer (1988: 115), en una línea parecida: "Conocemos el mundo de diferentes maneras, desde diferentes actitudes y cada una de las maneras en que lo conocemos produce diferentes estructuras o representaciones o, en realidad, realidades".

De hecho, en tanto se comunican y empalabran mediante el lenguaje, los seres humanos objetivan su personal apropiación de la realidad y edifican las certezas o las incertidumbres del presente, el pasado y el porvenir. Así elaboran enunciados y productos que pasan a integrar la realidad construida, la cual está más cerca de lo que el entorno considera real, que de lo real, propiamente (Van den Bulck, 1999: 6). Es más, las funciones otorgadas a la realidad por un sujeto dado nunca son intrínsecas y entrañan siempre una 'intencionalidad colectiva', (Searle, 1997: 41-42), que se encuentra dentro de cada observador. Gracias a ellas, los individuos comparten creencias, deseos, motivaciones o intenciones de la misma que, sin duda, condicionarán sus procesos de definición personal y socialización con los otros. Como ha expresado Lluís Duch (2010: 84) "Realidad es, de hecho, una construcción psicológica y sociológica, casi siempre transmitida de generación en generación, de tipo lingüístico: decimos, expresamos, empalabramos la realidad, lo que nos concierne, el cúmulo de relaciones positivas y negativas que configuran toda existencia humana"2.

Vista así, la realidad -más que un objeto o una experiencia unívoca “independiente de nuestra propia volición” -, (Berger y Luckmann, 2008: 11) podría ser entendida como “un argumento dentro de una explicación”, en palabras de Maturana (1996: 31). El investigador pone en cuestión que la realidad pueda ser independiente del sujeto observador y parte de la premisa de que los sujetos no pueden distinguir en la experiencia entre ilusión y percepción.

\footnotetext{
'Empalabrar' es un neologismo acuñado por Lluís Duch (1995) en sus aportaciones sobre el carácter logomítico del lenguaje. T. d. A.
} 
Esta perspectiva narrativa, que ha sido también secundada por los hermeneutas Wilhem Dilthey, Hans Georg Gadamer, Paul Ricoeur o por el filósofo John Searle, nos permite aproximarnos al modo en que los sujetos aprehenden la realidad social construida por los medios de comunicación. Para nosotros, el proceso comprensivo es eminentemente subjetivo. Como ha expresado Maturana, la realidad vivida por nosotros depende de la línea explicativa que adoptemos y ésta, a su vez, obedece al dominio emocional en el que nos encontremos en el momento de la explicación. Así planteada, la realidad cotidiana, además de ser configurada socialmente, también es construida psicológicamente y narrativamente. Por una parte, es proyectada y externalizada y, por otra, percibida e internalizada y, por lo tanto, necesariamente, mediada. Si bien es claro que no hay un acceso total o definitivo a lo que ocurre en la vida cotidiana -ya que toda percepción es perspectivística-, al mismo tiempo, cada vivencia de la realidad es real en tanto es vivida y puesta en palabras.

El individuo como ser "excéntrico", si utilizamos la terminología de Helmuth Plessner (1991), aprehende la realidad desde dentro y desde fuera o, lo que es lo mismo, está dentro y fuera de la realidad. Por lo tanto, la construcción de la misma sólo puede ser comprendida mediante una teoría capaz de estudiar las dimensiones objetivas y subjetivas de la acción individual y de la interacción social y comunicativa (Saperas, 1987).

Otro investigador que ha destacado el carácter discursivo de la realidad es Jesús González Requena (1989) quien diferencia entre la realidad y lo real: mientras que la primera - del lado del lenguaje- se caracteriza por su inteligibilidad y previsibilidad; el segundo - al margen de todo discurso- se afirma como lo asignificante e imprevisible. Lo real -dice Requena- no es transparente, sino esencialmente opaco y, por ello mismo, es necesaria una operación que lo vuelva inteligible: es aquí donde el lenguaje, el símbolo y la semiosis desempeñan su papel fundador. Así vista, la inteligibilidad es pues el resultado de una operación de discursivización (González Requena, 1989: 16) Y la realidad cotidiana solo puede ser aprehendida mediante las operaciones de simbolización.

\section{Incidencia de los medios de comunicación en la construcción de la realidad}

A partir los años 70 y, sobre todo, en los 80 numerosos investigadores de la comunicación, muy influidos por la sociología del conocimiento y la etnometodología, principalmente, comienzan a describir a los medios como constructores de la realidad (Hawkins y Pingree, 1983; Meyrowitz, 1985; Lindlof, 1987; Llull, 1988; Slater y Elliot, 1982). Tal y como han sugerido Hanna Adoni y Sherill Mane (1984), entre la multitud de conceptualizaciones y propuestas se pueden distinguir dos enfoques generales principalmente: uno que entiende la construcción de la realidad como un importante aspecto de la relación entre comunicación y cultura, y otro que la considera un tipo de efecto mediático.

Ahora bien, para nosotros, una de las propuestas más representativas, que se centra en cómo los contenidos mediáticos configuran las realidades simbólicas y en el grado de influencia que pueden llegar a tener estos en la vida social, es la teoría del cultivo. 
A pesar de presentar algunas limitaciones teóricas y metodológicas, los análisis de cultivo desarrollados por la Escuela de Annenberg pusieron de manifiesto la fuerza de la televisión como agente de socialización, y principal constructor de las imágenes y representaciones mentales compartidas. Su fundador, George Gerbner (1980), afirma que los contenidos televisivos son elementos de capital influencia en la conformación de la realidad social y que a mayor visionado de piezas existe un mayor número de respuestas televisivas. Esta última idea es, quizás, la que ha planteado más críticas ya que, en primer lugar, pueden existir otra serie de elementos que influyan en la apropiación de los contenidos y, en segundo, a nuestro juicio, es más importante el modo en el que los sujetos construyen los significados de las piezas que la cantidad de horas de visionado. Pero aún así, el análisis de los procesos de cultivo mantiene su vigencia.

No cabe la menor duda, de que, tal y como han expresado los discípulos de Gerbner, Michel Morgan, James Shanahan y Nancy Signoreli (2009: 35) “La recepción televisiva cultiva maneras de ver el mundo -y aquellos que pasan más horas 'viviendo' en el mundo televisivo son más propensos a ver el 'mundo real' en los términos de las imágenes, valores, retratos e ideologías que emergen a través de las lentes de la televisión”. Otras de las líneas de investigación del ámbito comunicativo que han tratado los procesos de construcción de la realidad son los enfoques dese la perspectiva de la agenda setting, que a pesar de no utilizar explícitamente el término 'construcción social de la realidad', tienen como uno de sus objetivos determinar hasta qué punto los temas incluidos en la agenda son considerados importantes por la audiencia (Lippman, 1922; Holbrook y Hill, 2005; McCombs y Shaw, 1972; McCombs y Reynolds, 2009; Scheufele, 2000; Wanta et al. 2004; Wanta y Ghanem, 2006); lo cual viene a ser una forma de delimitar el esquema de referencia compartido.

También desde las news framing o media framing se estudian los procesos de selección y construcción de los 'hechos sociales' y el modo en que las audiencias los interpretan (Entman, 1993; Gamson et al., 1992; Gitlin, 1980; Iyengar, 1991; Lester, 1980; Pan y Kosicki, 1993; Sieff, 2003 o Tuchman, 1978). Como es bien sabido, esta problemática es fundamental, ya que diversos estudios han evidenciado la habilidad de los medios para influir en el modo en que las audiencias perciben un evento, basándose en el modo en que lo presentan.

Más centradas en el impacto de la realidad simbólica en la recepción subjetiva de la misma, es decir, en la influencia de los contenidos mediáticos en las percepciones individuales de la realidad, podemos citar las aportaciones de Robert Hawkins y Suzanne Pingree (1980; 1982) sobre efectos televisivos o las de Steven H. Chaffee et al. $(1973 ; 1978)$ que aunque no utilizan el término 'construcción social de la realidad', sí que estudian el impacto de las realidades simbólicas en las imágenes subjetivas del dominio político. Para nosotros es esencial estudiar cómo influyen los contenidos simbólicos en la percepción subjetiva de la realidad. En El drama televisivo, Milly Buonanno (1999: 80) considera que es prácticamente imposible imaginar en la sociedad contemporánea "sistemas de representaciones de la realidad que no se elaboren y se construyan, sino en dependencia, en relación y en interacción con los sistemas de representación de los medios". 


\subsection{Discurso mediático y realidad cotidiana}

Dado que el entorno simbólico mediático ocupa la mayor parte de la vida cotidiana, gran parte de la realidad ocurre -tal y como ha sugerido Albert Bandura (2009) - a través de la aculturación electrónica. En "Social Cognitive Theory of Mass Communication", el investigador propone que los medios pueden implantar ideas acerca de la realidad mediante observación directa o indirecta de la misma. Aunque, a nuestro juicio, la distinción entre experiencia directa e indirecta no aporta elementos comprensivos relevantes, ya que toda realidad es mediada y simbólica y, por tanto, directa e indirecta a la vez; esta dicotomía evidencia que los medios pueden enseñar tanto nuevas formas de comportamiento, crear motivaciones para la acción o reforzar pautas ya aprendidas. Esto lo hacen alterando los valores preferentes de las personas, las creencias, las expectativas u otras percepciones.

Es cierto que también hay otras instituciones que proporcionan las motivaciones para llevar a cabo lo que se ha aprendido observacionalmente, como la familia, la escuela o el entorno de residencia. Incluso en algunos, el efecto de los medios puede ser totalmente mediado socialmente. De este modo, las personas que no tienen ningún contacto con los medios de comunicación pueden ser influidas por los receptores que sí tienen contacto (Bandura, 2009: 113). Esto explicaría por qué personas que carecen de acceso a los medios de comunicación (por carencia de recursos económicos) pueden aprehender los valores transmitidos gracias a otras personas que sí tienen acceso a los mismos.

Y es que la experiencia mediática aporta elementos y herramientas de comprensión de gran utilidad para la existencia del individuo en muchos sentidos, ya que le permite configurar los marcos de referencia, integrar, confirmar o corregir los mapas cognitivos preexistentes, gracias a los cuales construye la realidad social e, incluso, construir y modificar sus propias identificaciones subjetivas. De hecho, gran parte del aprendizaje social puede ser alcanzado de manera vicaria, es decir, observando, escuchando o leyendo algo que ocurre a otros en la distancia (Ortiz y Harwood, 2007).

A la hora de abordar el estudio de los medios como constructores de la realidad, existen diversas perspectivas teóricas. Hans-Mathias Kepplinger ha sugerido que hay tres grandes enfoques: el realismo, el expresionismo y el constructivismo (Scherer et al., 2005). Los realistas asumen la existencia de una realidad que puede ser experimentada y para ellos el objetivo de los medios es proporcionar una imagen exacta y verdadera de lo que es el "mundo real". Tarea a nuestro juicio más que imposible. En esta línea se realizaron sobre todo en los ochenta algunos estudios que analizaron la cobertura distorsionada de ciertos hechos y se concluyó que la ideología tiene un enorme poder en la configuración de las noticias (Greenberg, 1986; O’Keefe y Reid-Nas, 1987; Poindexter y Stroman, 1981; Rosengren, 1979; Sheley y Askins, 1981).

Los expresionistas, a juicio de Kepplinger, aceptan la existencia de una realidad objetiva también, pero le otorgan menor valor. Desde esta perspectiva, el objetivo de los medios sería más bien el de interpretar la realidad y darle un sentido so- 
cial (Kepplinger en Scherer et al, 2005: 1). Por último, los constructivistas-quizás el enfoque más aceptado en la actualidad-asumen que la realidad es construida socialmente hasta cierto punto y que los medios tienen un poderoso papel en este proceso.

\subsection{La preponderancia de los enfoques constructivistas}

Según K. Beck y K. Krippendorff (en Van den Bulck, 199: 5) existen cuatro tipos de constructivistas: los naive, bastante parecidos a los realistas de Kleppinger, que asumen la existencia de la realidad objetiva; los triviales, para quienes la realidad existe con independencia del observador, de modo que existe por una parte la realidad objetiva o primera y por otra, la interpretación de la misma o pseudorrealidad; los sociales, que consideran que nada existe fuera del lenguaje o la percepción humana; y, los radicales, para quienes incluso la realidad objetiva o física, propiamente, es una construcción.

Esta última orientación constructivista está ligada, sobre todo, a la difusión de la sociología de Schütz y sus discípulos, Peter Berger y Thomas Luckmann y a la aparición de numerosas obras clave que aplican estos planteamientos al estudio de la comunicación mediática (Reese, Gandy y Grant, 2001). Este enfoque considera que los medios influyen activamente en la construcción de la realidad cotidiana de los receptores. Así lo han sugerido, desde perspectivas diversas, los autores mencionados, y otros (Blumler y Gurevitch, 1982; Carter, 2013; Gamson y Modigliani, 1989; Hall, 1982; Meyrowitz, 1985; Lindlof, 1987; Llull, 1988; Pan y Kosicki, 1993; Sieff, 2003), por citar algunos referentes clásicos.

Aunque algunos investigadores ya advirtieron en los ochenta de los peligros que podía suponer una hipersignificación del poder de los medios en la construcción de la realidad (Wolf, 1986 o Slater y Elliot, 1982), para nosotros es imposible separar los modos de actuar, pensar y sentir de los individuos de la comediación, estructura de acogida esencial (Duch, 2010) que, sin duda, ejerce una poderosa influencia en la contrucción de la realidad.

Si bien la clasificación de enfoques presentados hasta el momento (realistas, expresionistas y construccionistas) pueden considerarse interesantes, a nuestro juicio la perspectiva constructivista es, sin duda, la más acertada. Pero aún así, creemos que sería interesante completarla para poderlo aplicar a la incidencia de los medios en la percepción y cognición de la realidad cotidiana.

A pesar de que la intersubjetividad y la comunicación interpersonal-el encuentro con el otro- son esenciales en la configuración del mundo de la vida cotidiana y la realidad subjetiva, no podemos olvidar que la experiencia mediática (recepción y participación virtual) también es clave en la configuración social de la realidad.

El concepto de 'realidad social simbólica', propuesto Hanna Adoni y Sherrill Mane (1984), puede resultar apropiado para abordar esta experiencia. Las autoras se refieren a cualquier forma de realidad objetiva que pertenece a un sistema simbólico dado, tal como el arte, la literatura o los contenidos mediáticos. Para ellas existen diferentes realidades simbólicas 
que se diferencian por los diferentes sistemas simbólicos a los que pertenecen y el proceso de construcción de la realidad social debe ser entendido como un proceso dialéctico donde se interrelacionan tanto la realidad objetiva, como la simbólica y la subjetiva. Las investigadoras también han puesto de manifiesto en un estudio empírico que algunas percepciones o experiencias indirectas de la realidad (a través del visionado mediático) son más intensas que experiencias directas. De este modo, vivencias individuales, que no han tenido por qué ser compartidas activamente o experimentadas en primera persona, pueden pasar a formar parte del conocimiento general a través del lenguaje o la narración mediática.

Tal y como han evidenciado Berger y Luckmann (2008: 89), una historia puede describir la realidad social y sedimentarla, es decir, convertirla en una experiencia reconocible y memorable; pero al mismo tiempo suele contener imágenes del orden social y legitimarlo. Esta legitimación posee dos funciones: primero, proporcionar una explicación de la realidad objetiva; y segundo, hacer que esta explicación sea aceptable. De manera que los receptores adquieren un aprendizaje social determinado, al tiempo que aceptan éste como perteneciente a la realidad objetiva y compartida.

Pero ¿cómo se percibe, comprende y construye esta realidad? Las variaciones explicativas podrían ser múltiples, aunque casi todas deberían basarse en el siguiente postulado básico: que los sujetos y los grupos se nutren de una serie de principios significativos que son vehiculados por las instituciones, entre las que cabe mencionar muy especialmente a los medios de comunicación. Y, sobre todo, que gracias a esta serie de estructuras mentales o esquemas de conocimiento, que contienen información sobre la realidad y contenidos procedimentales, pueden comunicarse y vivir en sociedad.

\section{El poder de los media frames}

Una de las cuestiones más interesantes a este respecto es el proceso mediante el cual los medios de comunicación prestan esquemas de significación a nuestro sentido común y a nuestra experiencia cotidiana, convirtiéndose en marcos de referencia desde los que actuamos y vivimos en sociedad. Los media frames son principios organizativos que se comparten socialmente y constituyen la estructura simbólica y significativa del mundo social. Más específicamente, a juicio de Reese (2001) son principios organizadores que son socialmente compartidos y persisten en el tiempo, trabajan de manera simbólica para dar sentido a la realidad social. Recordemos que los frames son esquemas significativos sirven a los individuos para interpretar el mundo circundante y les permiten situarse en un determinado contexto (Goffman, 2006; Etnman, 1993). Precisamente las narrativas mediáticas tienen un papel fundamental en el enmarcamiento interpretativo de la realidad y en la fijación del marco dominante (Sampedro, 2003).

Además, tal y como ha subrayado James Curran et al (1998: 201), estos marcos favorecen la integración dentro del orden normativo y resaltan los límites de lo que es aceptable y de lo que no lo es. Dicho con otras palabras, definen la realidad y legitiman el orden social. Por su parte, la investigadora Elena Galán (2007) ha sintetizado, recientemente, que la audiencia, voluntaria o involuntariamente, integra diversos esquemas cognitivos y emocionales entre los que cabría destacar: 
modelos humanos para la construcción de la identidad, formas de interacción social, dinámicas vitales, líneas éticas y planteamientos sociopolíticos. Estos modelos o esquemas posibles no sólo construyen y enmarcan la realidad a través de conceptos, imágenes o metáforas de carácter simbólico, sino que también ofrecen una determinada representación del mundo. Y estas imágenes que circulan en los medios de comunicación son las que, a menudo, contribuyen a consolidar el orden social o a construir puntos de vista alternativos al discurso hegemónico (Menéndez, 2006).

No olvidemos que, a un nivel teórico, los media frames-que proponemos en un sentido goffmaniano- tienen un carácter multifuncional. En primer lugar, construyen el conocimiento básico -el marco explicativo- que el sujeto receptor debe codificar e interpretar. En segundo lugar, proponen mecanismos de selección atencional. De esta manera, el sujeto tiende a procesar aquella información que encaja en dicho esquema y a desechar la información que, desde el punto de vista del esquema, se considera irrelevante (Kintsch y Van Dijk, 1978). En tercer lugar, generan expectativas de lo que va a ocurrir, de forma que los sujetos pueden inferir consecuencias. En cuarto lugar, establecen metas o proponen modelos de conducta social ideales, que pueden servir de referentes a los sujetos receptores. En quinto lugar, identifican y categorizan objetos y situaciones que proporcionan significaciones posibles para comprender la realidad.

Así mismo, estos esquemas proponen evaluaciones o valoraciones de la información propuesta, de modo que funcionan como modelos pautados de comprensión (Aruguete, 2012; García Marín, 2011; Mariño, 2010). Pero, sobre todo, convierten la amorfa realidad en una estructura significativa (Gitlin, 1980).

\section{1. media frames, entre la configuración y la refiguración}

Es importante destacar que la relevancia de los marcos primarios es two-fold para la investigación comunicativa, tal y como han sugerido David Tewksbury y Dietram A. Scheufele (2009: 17-33). Primero, los marcos son sistemas de categorías sociales que sirven como importantes herramientas para procesar la información entre los ciudadanos. Segundo, el discurso social y mediático es, a menudo, dirigido hacia marcos específicos para influir en las percepciones de la audiencia.

Las aproximaciones a la investigación de frames comunicativos se podrían englobar en dos categorías, según los investigadores: 1) Frame building, que serían aquellos estudios dedicados a cómo los frames se configuran y establecen en el discurso social. Y 2) Frame setting: los estudios centrados en los efectos de los frames en las audiencias. A la luz de estos planteamientos, los esquemas mediáticos tienen un papel crucial tanto en la fase de configuración de la realidad cotidiana, como en la de refiguración subjetiva, donde esta realidad es aprehendida por los sujetos y los colectivos.

1) En el proceso de configuración o frame building los esquemas mediáticos permiten transformar el universo de las realidades objetivas (los acontecimientos, que forman parte de la paramount reality) en narraciones mediáticas (los relatos de los acontecimientos). Así, estos marcos precomprensivos -de tenor arquetípico, típico y estereotípico-construyen la 
realidad de manera simplificada (Gitlin, 1980; Tankard et al. 1991; Snow y Benford, 1988). Como ha subrayado Robert Entman (1993: 52), el framing consiste en seleccionar algunos aspectos de una realidad percibida y hacerla más comprensible en una pieza, de modo que promueva una definición particular de un problema, una interpretación causal y evaluación moral, o un tratamiento recomendado.

En el tratamiento de noticias este proceso es bastante evidente: no sólo se presta atención a unos acontecimientos y se silencia otros, sino que también se evalúa una situación dada y se categoriza a los personajes que la representan. En definitiva, los marcos mediáticos no sólo describen qué está pasando, sino que valoran y diagnostican de acuerdo con una ideología concreta (Entman, 1993: 6-27) o, lo que es lo mismo, ofrecen una guía para comprender y juzgar el mundo.

2) En el proceso de refiguración o frame setting los marcos mediáticos intervienen en procesos tan dispares como la percepción, la comprensión, la memoria y la organización de la conducta. Estos esquemas cognitivos otorgan sentido y ofrecen horizontes posibles -mundos posibles, si utilizamos la acepción inaugurada por Leibniz- desde los que interpretar las piezas mediáticas. Como ha expresado Murray Edelman (1993: 232), el mundo social es un caleidoscopio de realidades potenciales y cada una de ellas puede ser evocada alternando el punto de vista o modo en que son encuadradas y categorizadas. Así visto, el modo en que un sujeto interpreta una pieza mediática se desarrolla en relación a un marco determinado.

\subsection{Carácter interpretativo de los media frames}

Ya en 1967, el psicólogo social Muzafer Sherif demostró que todos los juicios individuales y percepciones ocurren a través de ciertos marcos de referencia. La experiencia y la conducta individual, por lo tanto, no pueden entenderse sin las influencias de los grupos y la cultura que los rodea, como ya sugerimos. Para Sherif (1967), el campo de la psicología social está constituido por el estudio de la interacción que se produce entre los ámbitos individual, grupal y cultural en la formación de cualquier experiencia y conducta particular. Desde esta perspectiva, las concepciones subjetivas se encuentran relacionadas con los marcos interpretativos que un individuo utiliza -que se encuentran, a su vez, propuestos en las piezas mediáticas.

Como han apuntado los comunicólogos David Tewksbury y Dietram A. Scheufele (2009: 19), "los marcos informativos pueden ejercer una relativamente sustancial influencia en las creencias, actitudes y comportamiento de los ciudadanos". Los frames, en este sentido, son herramientas que construyen las asociaciones entre conceptos y ayudan a las audiencias a crear o realizar conexiones asociativas entre un hecho y consideraciones relevantes para su definición, causas, implicaciones y tratamiento; son, en definitiva, "paquetes" de argumentos, información, símbolos, metáforas e imágenes, si utilizamos la descripción de William Gamson y André Modigliani (1987), que pueden afectar la manera en que las personas entienden, interpretan y reaccionan ante un problema en cuestión (Tewksbury y Scheufele, 2009). 
Es importante recalcar que los efectos de los frames son interpretativos, es decir, afectan a la manera en que se dilucida un hecho (Brewer, 2005; Shen, 2009). Y, por lo tanto, muestran aspectos significativos de la realidad percibida que deben ser apropiados subjetivamente. Pero, también, estos contenidos nos acercan a mundos 'imposibles', inaccesibles o diferentes al propio, que se hallan en los límites de los marcos o fuera de ellos. Es decir, hacen percibir aquello que en la vida diaria, o en el marco sociocultural, nunca o difícilmente podría experimentarse. Tal y como menciona John B. Thompson (1998: 291): "Los medias ponen a disposición de los individuos un amplio abanico de experiencias que los individuos, por lo general no adquirirían en los contextos habituales en los que se desarrolla su vida cotidiana".

No obstante, los media frames también pueden crear vínculos con las creencias o valores preexistentes. De modo que activan o refuerzan constructos personales que se encuentran complicados con otras fuentes de aprendizaje social o con la propia trayectoria biográfica o la memoria cultural del grupo. Estudiar cómo los medios de comunicación contribuyen a la construcción social de la realidad, por tanto, implica focalizar tanto en las facticidades transmitidas a través de los marcos, como en el impacto que dichas representaciones simbólicas tienen en la percepción subjetiva de la realidad.

\section{Recapitulación y futuras líneas de investigación}

En definitiva, el discurso mediático facilita repertorios de expresiones, símbolos y figuras retóricas que son retomadas, actualizadas y reinterpretadas en diferentes ocasiones, convirtiéndose muchas veces en la materia significativa de la realidad cotidiana. De la misma manera, los relatos mediáticos activan cuadros comunicativos que confirman o desmienten las jerarquías sociales reconocidas, es decir, representan y fijan el marco interpretativo donde los individuos se insertan y, al mismo tiempo, muestran cuáles son las actitudes plausibles y cuáles las conductas 'desviadas' dentro de una sociedad. A la luz de la literatura científica revisada podemos concluir que estos esquemas o marcos de referencia psicológicos funcionan como recursos sociales que sirven a los individuos para comprenderse y construir sus identificaciones en relación a los diferentes roles que realizan en sociedad. Pero, también y, sobre todo, para comprender la actitud o ideología de los demás individuos que conforman los diferentes grupos.

En este sentido, es necesario no perder de vista que los medios de comunicación son instituciones socializadoras que facilitan la comprensión del entorno, y permiten a los individuos y a los grupos contextualizarse. Lo que implica que las investigaciones sobre media frames no deben obviar el alcance social y psicológico de los marcos sobre los individuos y los grupos. Precisamente, como hemos anotado, los medios -mediante sus marcos- vehiculan narrativas identitarias, crean imaginarios mediáticos, y condicionan la memoria y la tradición cultural y comunicativa compartida por los miembros de una comunidad (Sola Morales, 2012). Todos ellos son temas de gran interés que pueden ser abordados a la luz de las claves comprensivas que ofrecen los media frames y, que sin embargo, han sido aún poco investigados. 
Además, los medios contribuyen a conformar y configurar la realidad cotidiana de los individuos y los grupos, ya que tienen una poderosa influencia en la definición y representación de los sistemas simbólicos, cognitivos y afectivos a través de los cuales se configura la misma. Hecho por el cual la investigación en media frames debe seguir avanzando en la comprensión de diversos mecanismos interpretativos, tales como la adscripción de valores, creencias o aptitudes que se ven motivados necesariamente por los discursos mediáticos y por la participación virtual.

Finalmente, valga añadir que las llamadas realidad y participación virtual, mediaciones cada vez más preponderantes, abren nuevos interrogantes y desafíos acerca de la construcción de la realidad cotidiana misma que, sin duda, merecería la pena seguir abordando desde la perspectiva de los media frames.

\section{Referencias bibliográficas}

Adoni, H. y Mane, Sh. (1984): "Media and the Social Construction of Reality. Toward an Integration of Theory and Research", Communication Research, n. 11(3), julio, pp. 323-324.

Aruguete, N. (2012): “Encuadres mediáticos y su percepción pública”, Psicología Política, n.44, pp. 7-29.

Bandura, A. (2009): “Social Cognitive Theory of Mass Communication”, en Bryant, Jennings y Oliver, Mary B. (eds.): Media Effects. Advances in Theory and Research. Nueva York, NY: Routledge, pp. 94-124.

Berger, P. L. y Luckmann, Th. (2008): La construcción social de la realidad. Buenos Aires: Amorrortu Editores.

Berne, E. (1966): Juegos en los que participamos: Psicología de las relaciones humanas. México: Editorial Diana.

Blumler, J. G. y Gurevitch, M. (1982): “The Political Effects of Mass Communication”, en Gurevitch, M. et al. (comps.): Culture, Society and the Media. Londres: Methuen.

Brewer, P. R. (2005): “Values, Framing and Citizen's Thoughts about Policy Issues: Effects on Content and Quantity”, Political Psychology, n. 26(6), diciembre, pp. 929-948.

Bruner, J. (1984): Acción, pensamiento y lenguaje. Madrid: Alianza Editorial.

- (1996): Realidad mental y mundos posibles. Los actos de la imaginación que dan sentido a la experiencia. Barcelona: Editorial Gedisa.

Buonanno, M. (1999): El drama televisivo. Identidad y contenidos sociales. Barcelona: Editorial Gedisa.

Carter, M. J. (2013): “The Hermeneutics of Frames and Framing: An Examination of The Media's Construction of Reality”, Sage open, april-june, pp. 1-12.

Cassirer, E. (1998): Filosofía de las formas simbólicas. El lenguaje, vol. 1. México: Fondo de Cultura Económica. 
Chaffee, S. H; Ward, L. S. y Tipton, L. P. (1973): “Mass Communication and Political Socialization”, en Dennis, Jack (ed.): Socialization to Politics: A Reader. Nueva York, NY: John Wiley \& Sons, pp. 391-409.

Chaffee, S. H. et al. (1977): "Mass Communication in Political Socialization”, en Renshon, Stanley A. (ed.): Hanbook of Political Socialization. Nueva York, NY: Free Press, pp. 223-258.

Chillón, A. (2007): “Hacer los hechos. Un ensayo de fenomenología de los 'hechos sociales'”, Ars Brevis, n. 13, Universitat Ramon Llull, Barcelona, pp. 27-50.

Curran, J. (1998): “Repensar la comunicación de masas”, en Curran, J.; Morley, D. y Walkerdine, V. (comps.): Estudios culturales y comunicación. Análisis, producción y consumo cultural de las políticas de identidad y el posmodernismo. Barcelona: Paidós.

Duch, Ll. (1995): Mite i cultura. Barcelona: Publicacions de l'Abadia de Montserrat.

- (2010): Religió i comunicació. Barcelona: Fragmenta Editorial.

- Chillón, A. (2012): Un ser de mediaciones. Antropología de la comunicación, vol. 1. Barcelona: Herder Editorial.

Dunn, M. G. (1977): “Creating reality: How TV news disorts events”, Contemporary Sociology, n. 6, pp. 546-547.

Eco, U. (1986): La estrategia de la ilusión. Barcelona: Editorial Lumen.

Edelman, M. (1993): “Contestable Categories and Public Opinion”, Political Communication, n. 10(3), pp. 231-242.

Entman, R. M. (1993): “Framing: Toward Clarification of a Fractured Paradigm”, Journal of Communication, n. 43(4), diciembre, pp. 51-58.

Ericson, R. V. (1998): "How journalists visualice fact", Annals of the American Academy of Political and Social Science, $\mathrm{n}$. 560, pp. 83-95.

Frunza, S. (2011): "Media Communication and the Politics of the Symbolic Construction of Reality", Journal for the Study of Religions and Ideologies, vol. 19, no. 29, pp.182-202.

Galán, E. (2007): La imagen social de la mujer en las series de ficción. Cáceres: Publicaciones de la Universidad de Extremadura.

Gamson, W. A. et al. (1992): "Media Images and the Social Construction of Reality", Annual Review of Sociology, vol. 18, pp. 373-393.

- Modigliani, A. (1989): "Media discourse and public opinion on nuclear power: A constructionist approach", American Journal of Sociology, n. 95, pp.1-37.

- Modigliani, A. (1987): “The Changing Culture of Affirmative Action”, Research in Political Sociology, n. 3(2), pp. 137-177. García Marín, J. (2011): “Encuadres, conflictos y efectos de agenda”, Zer, n. 31, pp. 167-181. 
Gerbner, G. et al. (1980): “Aging with Television: Images on Televisión Drama and Conceptions of Social Reality”, Journal of Communication, n. 30(1), marzo, pp. 37-47.

Giddens, A. (1995): Modernidad e identidad del yo. El yo y la sociedad en la época contemporánea. Barcelona: Editorial Península.

Gitlin, T. (1980): The Whole World Is Watching: Mass Media in the Making and Unmaking of the New Left. Berkeley, CA: University of California Press.

Goffman, E. (2006): Frame Analysis. Los marcos de la experiencia. Madrid: Centro de Investigaciones Sociológicas.

Gónzalez Requena, J. (1989): El espectáculo informativo o la amenaza de lo real. Madrid: Editorial Akal.

Goodman, N. (1984): On Mind and Other Matters. Cambridge, MA: Harvard University Press.

Greenberg, B. S. (1986): “Minorities and the Mass Media”, en Bryant, J. y Zillmann, D. (eds.): Perspectives on Media Effects. Hillsdale, NJ: Lawrence Erlbaum Associates, pp.165-188.

Hall, S. (1982): “The rediscovery of “Ideology”: Return of the repressed in media studies”, en Gurevitch, M. et. al. (eds.): Culture, Society and the Media. London, England: Metheun.

Hartley, J. (1996): Popular reality. London, England: Arnold.

Hawkins, R. P. y Pingree, S. (1980): “Some Processes in the Cultivation Effect”, Communication Research, n. 7(2), abril, pp. 193-226.

- (1982): “Television Influence on Constructions of Social Reality”, en Pearl, D.; Bouthilet, L. y Lazar, J. B. (eds.): Television and Behavior: Ten Years of Scientific Progress and Implications for the Eighties. Washington, DC: Technical Reports. U. S. Government Printing Office, pp. 224-247.

Holbrook, R. A. y Hill, T. G. (2005): "Agenda-setting and Priming in Prime Time Television: Crime Dramas as Political Cues", Political Communication, n. 22(3), pp. 277-295.

Iyengar, S. (1991): Is Anyone Responsible? Chicago, IL: University of Chicago Press.

Kintsch, W. y Van Dijk, T. A. (1978): “Toward a Model of Text Comprehension and Production”, Psychological Review, n. 85(5), septiembre, pp. 363-394.

Lindlof, T. R. (comp.) (1987): Natural Audiencies. Qualitative Research of Media Uses and Effects. Norwood, NJ: Ablex Publications.

Lippmann, W. (1922): Public Opinion. Londres: George Allen \& Unwin.

Lester, M. (1980): “Generating newsworthiness: The interpretative construction of public events”, American Sociological Review, n. 45, pp. 984-994.

Llull, J. (1988): World Families Watch Television. Newbury Park, CA: Sage Publications. 
Luhmann, N. (2000): La realidad de los medios de masas. Barcelona: Anthropos.

Mariño, M. V. (2010): “Agendas, encuadres y discursos en los noticiarios televisivos españoles durante la crisis del Prestige”, Athenea Digital, n. 19, pp. 249-257.

Martín Barbero, J. (1987): De los medios a las mediaciones. México: Gustavo Gili.

Maturana, H. (1996): La realidad: ¿objetiva o construida? Barcelona: Anthropos.

McCombs, M. E. y Reynolds, A. (2009): “How the News Shapes our Civic Agenda”, en Bryant, J. y Oliver, M. B. (eds.): Media Effects. Advances in Theory and Research. Nueva York, NY: Routledge, pp. 1-17.

- Shaw, Donald L. (1972): “The Agenda-setting Function of Mass Media”, Public Opinion Quarterly, n. 36(2), pp. 176-187.

Menéndez, M. I. (2006): Discursos de ficción y construcción de la identidad de género en televisión. Palma de Mallorca: Publicacions de l’Universitat de les Illes Balears.

Meyrowitz, J. (1985): No Sense of Place: The Impact of Electronic Media on Social Behaviour. Nueva York, NY: Oxford University Press.

Morgan, M.; Shanahan, J. y Signoreli, N. (2009): “Growing Up with Television: Cultivation Processes”, en Bryant, J. y Oliver, M. B. (eds.): Media Effects. Advances in Theory and Research. Nueva York, NY: Routledge, pp. 34-49.

O'Keefe, G. y Reid-Nash, K. (1987): “Crime News and Real-world Blues”, Communication Research, n. 14(2), abril, pp.147163.

Ortiz, M. y Harwood, J. (2007): "A Social Cognitive Theory Approach to the Effects of Mediated Intergroup Contact or Intergroup Attitudes", Journal of Broadcasting and Electronic Media, n. 51(4), pp. 615-631.

Pan, Z., \& Kosicki, G. M. (1993): “Framing analysis: An approach to news discourse”, Political Communication, n. 10, pp. 5575.

Pintos, J. L. (2005): “Comunicación, construcción de la realidad e imaginarios sociales”, Utopía y praxis latinoamericana, Año 10, n. 29, abril-junio, pp. 37-65.

Plessner, H. (1991): “Conditio Humana”, en Mann, G. y Heuss, A. (eds.): Historia Universal. Prehistoria. Las primeras culturas superiores, vol. 1. Madrid: Editorial Espasa Calpe, pp. 31-85.

Poindexter, P. M. y Stroman, C. A. (1981): "Blacks and Television: A Review of the Research Literature”, Journal of Broadcasting, n. 25(2), pp. 103-122.

Reese Stephen D. (2007): “The Framing Project: A Briding Model for Media Research Revisited”, Journal of Communication, n. 57(1), marzo, pp. 148-154.

Reese, S. D. (2001): “Prologue—Framing public life”, en Reese, S. D.; Gandy Jr., O. H. y Grant, A. E. (eds.): Framing public life: Perspectives on media and our understanding of the social world. Mahwah, NJ: Lawrence Erlbaum. 
- Gandy, O. H., Jr. \& Grant, A. E. (2001): Framing public life: Perspectives on media and our understanding of the social world. Mahwah, NJ: Lawrence Erlbaum.

Rosengren, K. E. (1979): “Bias in News. Methods and Concepts”, Studies of Broadcasting, n. 15, pp. 37-45.

Sampedro, V. F. (2003): La pantalla de las identidades. Medios de comunicación, políticas y mercados de identidad. Barcelona: Icaria Editorial.

Saperas, E. (1987): Los efectos cognitivos de la comunicación de masas. Las recientes investigaciones en torno a los efectos de la comunicación de masas (1970-1986). Barcelona: Editorial Ariel.

Scherer, H; Arnold, A-K.; y Schlütz, D. (2005, mayo): "Media’s Creating Reality: Construction as a Social Process”, Comunicación presentada en la Conferencia anual de la ICA (International Communication Association), Nueva York.

Scheufele, D. A. (2000): "Agenda-setting, Priming, and Framing Revisited: Another Look at Cognitive Effects of Political Communication", Mass Communication and Society, n. 3(2), pp. 297-316.

Schrape, J. F. (2011): “Social Media, Massenmedien und gesellschaftliche Wirklinchkeitskonstruktion”, Berlin J Sozion, n. 21, pp. 407-429.

Schütz, A. (2003): El problema de la realidad social. Buenos Aires: Amorrortu.

Searle, J. (1997): La construcción de la realidad social. Barcelona: Paidós.

Sheley, J. F. y Askins, C. D. (1981): “Crime, Crime News, and Crime Views”, Public Opinion Quarterly, n. 45(4), pp. 492-506. Shen, F. (2009): “Effects of News Frames and Schemas on Individuals's Issue Interpretations and Attitudes”, Journalism and Mass Communication Quarterly, n. 81(2), pp. 400-416.

Sherif, M. (1967): Social Interaction: Processes and Products. Chicago, IL: Aldine Press.

Sieff, E. (2003): “Media frames of mental illnesses: The potential impact of negative frames”, Journal of Mental Health, n. 12, pp. 259-269.

Slater, D. y Elliot, W. R. (1982): “Television's Influence on Social Reality”, Quartely Journal of Speech, n. 68(1), febrero, pp. 6979.

Snow, D. A. y Benford, R. D. (1988): “Ideology, Frame Resonance and Participant Mobilization”, International Social Movement Research, n. 1(1), pp. 197-217.

Sola Morales, S. (2013a): "Hacia una tipología de narrativas mediáticas identitarias”, Sphera Pública, n. 13, vol. 2, pp. 30-48.

- (2013b): “Mediatic Narratives and Identification processes. A theoretical and methodological approach", Revista Orbis, n. 24 (8), pp. 36-50.

- (2012): “La dialéctica entre las narrativas mediáticas y los procesos de identificación”. Tesis doctoral. Departamento de Medios, Comunicación y Cultura. UAB. 
Strauss, A. (1959): Mirrors and Masks. Nueva York, NY: Free Press.

Tankard, J. et al. (1991): "Media frames: Approaches to conceptualization and measurement”, Paper presented to the Association for Education in Journalism and Mass Communication, Boston, MA.

Tewksbury, D. y Scheufele, D. A. (2009): “News Framing Theory and Research”, en Bryant, J. y Oliver, M. B. (eds.): Media Effects. Advances in Theory and Research. Nueva York, NY: Routledge, pp. 17-33.

Tuchman, G. (1978): Making news. New York, NY: The Free Press.

Van den Bulck, J. (1999): “Mediation: Toward a Media Theory of the Social Construction of Reality”, Communicatio: South African Journal for Communication Theory and Research, n. 25(1), mayo, pp. 3-11.

Wanta, W. y Ghanem, S. (2006) “Effects of Agenda-setting”, en Preiss, R. et al. (eds.): Mass media theories and processes: Advances through meta-analysis. Mahwah, NJ: Lawrence Erlbaum Associates, pp. 37-52.

Wanta, W., Golan, G. y Lee, C. (2004): "Agenda-setting and International News: Media Influence on Public Perceptions of Foreign Nations”, Journalism and Mass Communication Quartely, n. 81(2), pp. 364-377.

Watzlawick, P. (2003): ¿Es real la realidad? Confusión, desinformación, comunicación. Barcelona: Herder Editorial.

- (comp.) (1988): La realidad inventada. ¿Cómo sabemos lo que creemos saber? Barcelona: Editorial Gedisa.

Wolf, M. (1986): “Le discrete infuenze.” Problemi dell'Informazione, n. 21(4), diciembre, Bolonia, pp. 481-492. 